\title{
A 63-year-old returned traveller with fever, rash, hepatitis and eosinophilia
}

\author{
Samira Jeimy MD PhD, Kathryn McRae MD, Reena Pattani MDCM MPH
}

Cite as: CMAJ 2018 July 9;190:E831-5. doi: 10.1503/cmaj.171134

A 63-year-old woman presented to the emergency department with a one-week history of headache, joint pain, rash and fever. The rash had begun on her thighs and progressed to involve her whole body within 48 hours. She did not report gastrointestinal, genitourinary or respiratory symptoms, and there was no history of unintentional weight loss. She had returned three months previously from Mongolia, Cambodia and Vietnam, and had received appropriate travel vaccinations. She did not smoke, drink alcohol or use any recreational substances.

For the past one month, she had been treated with sulfasalazine for seronegative rheumatoid arthritis, with bilateral erosive metacarpal involvement. Her family history included rheumatoid arthritis. She also had self-limited chronic urticaria with dermatographism, ductal carcinoma in situ treated curatively with lumpectomy, tubular adenomas on screening colonoscopy and presumed hepatitis in childhood. She was born in the Philippines but had lived in Canada for several decades. Aside from occasional use of acetaminophen, our patient took no other over-thecounter or naturopathic medications.

On examination, our patient was alert and in no apparent distress, with a body temperature of $38.2^{\circ} \mathrm{C}$. She had bilateral periorbital edema. There was no lymphadenopathy. There was a nonblanching, erythematous, morbilliform rash that spared the palms and soles but no bullous lesions, skin scaling or mucosal lesions. She had deformities in her hands consistent with rheumatoid arthritis but no active joints and normal grip strength. Cardiac and respiratory examinations were normal, and she did not have hepatosplenomegaly or stigmata of cirrhosis. Her neurologic examination was normal, with negative results for Brudzinski sign, Kernig sign and jolt accentuation.

\section{What diagnoses should be considered in this patient?}
a. Primary hypereosinophilic syndrome
b. Parasitic infection
c. Drug reaction with eosinophilia and systemic symptoms (DRESS) syndrome
d. Eosinophilic granulomatosis with polyangiitis
e. Adult-onset Still disease

Both (b) and (c) are correct. Fever has many possible causes, including infectious and noninfectious etiologies. Given the patient's recent travel and concomitant eosinophilia, we considered parasitic infection, because it can occur in the absence of a localizing symptom like diarrhea. Of noninfectious etiologies, we considered inflammatory and neoplastic causes, as well as drug reactions.

Eosinophilia is a hallmark of hypersensitivity reactions and may be associated with systemic symptoms. Drug reactions that should be considered medical emergencies in a setting of eosinophilia, fever, rash and a recent change in medications include Stevens-Johnson syndrome and toxic epidermal necrolysis (which comprise a spectrum of the same disease), and drug reaction with eosinophilia and systemic symptoms, an important consideration in our patient.

Primary hypereosinophilic syndrome (a) describes a group of clonal diseases characterized by an overproduction of eosinophils (for which there is no identifiable underlying cause), with infiltration of target organs. The condition is marked by dysfunction of the affected organs. Investigations may include routine blood tests to measure the extent of organ involvement and tests to rule out secondary causes of eosinophil overproduction. In the absence of a secondary cause, a serum tryptase level may point towards a myeloproliferative disorder. At this stage, there were many potential secondary causes for eosinophil overproduction, and we felt it was too early to consider this diagnosis.

Eosinophilic granulomatosis with polyangiitis (d) should also be considered when eosinophilia is associated with rheumatologic symptoms such as rash and joint pain. However, our patient did not have atopic features, and her rash was atypical of eosinophilic granulomatosis with polyangiitis, which tends to present as palpable purpura. Another inflammatory consideration, adultonset Still disease (e), is characterized by daily fever, joint pain and typical evanescent salmon-coloured rash that primarily affects the trunk.

Based on our differential diagnosis (Box 1), we investigated infectious, allergic and inflammatory causes. The patient's initial laboratory investigations (Box 2) showed leukocytosis (driven by atypical lymphocytosis and eosinophilia) and mixedpattern hepatitis. Inflammatory markers, including C-reactive protein level, erythrocyte sedimentation rate and ferritin level, were elevated. 


\section{How should this patient be evaluated further?}

a. Bone marrow aspiration and biopsy

b. Skin biopsy of the eruption

c. Further autoimmune work-up including repeat rheumatoid factor and anti-cyclic citrullinated peptide antibodies

d. Reverse transcriptase-polymerase chain reaction (RT-PCR) of peripheral blood for FIP1L1-PDGFRA gene fusion

e. Computed tomography (CT) of the thorax, abdomen and pelvis

The answer is (b). Given the initial findings and the patient's persistent rash, lymphocytosis and hepatitis, we now considered drug reaction with eosinophilia and systemic symptoms syndrome as the underlying cause. Skin biopsy showed mild dermal perivascular lymphocytic infiltrate, focal spongiosis and interface dermatitis, findings compatible with drug-induced dermatitis (Figure 1).

Bone marrow aspiration and biopsy (a) are indicated when investigating primary hypereosinophilic syndrome, chronic eosinophilic leukemia and other hematologic neoplasms involving clonal eosinophil expansion. Similarly, FIP1L1-PDGFRA fusion genes (d) are present in myeloproliferative hypereosinophilic syndromes. Our patient had no clinical features that suggested a hematologic malignant disease such as lymphadenopathy, splenomegaly or more classic derangements on complete blood cell count. In addition, eosinophilia is often greater in cases of malignant disease (in our experience, eosinophil counts of $1.5 \times 10^{9} / \mathrm{L}$ or more). Therefore, we did not add RT-PCR of peripheral blood and bone marrow analyses to this round of investigations, and we did not undertake further autoimmune work-up or imaging (e) because our patient did not have a history of asthma or palpable purpura that suggested eosinophilic granulomatosis with polyangiitis. Repeating serological testing (c) would not have been helpful in following disease activity of rheumatoid arthritis.

Matching our findings to the validated diagnostic criteria provided by the RegiSCAR project (Box 3), ${ }^{1}$ we came to a probable diagnosis of drug reaction with eosinophilia and systemic symptoms (DRESS) syndrome related to sulfasalazine therapy.

\section{Discussion}

Drug reaction with eosinophilia and systemic symptoms syndrome is a subset of type IV drug-induced hypersensitivity reactions, with an incidence of about 1 in 10000 drug exposures. ${ }^{2}$ It characteristically occurs two to six weeks after the drug is started and is distinct from more common drug rashes because of the longer duration of symptoms and systemic involvement. ${ }^{2}$ Common precipitants include antiepileptic agents and sulfonamide medications. In one retrospective case series, 4 of 38 cases of DRESS syndrome were caused by sulfonamides. ${ }^{3}$ In another retrospective review of 172 cases of the syndrome, 10 were precipitated specifically by sulfasalazine. ${ }^{4}$

\section{Clinical presentation}

Drug reaction with eosinophilia and systemic symptoms syndrome is a clinical diagnosis. Fever, lymphadenopathy, facial edema and pruritus herald the onset of diffuse, maculopapular eruption, which may progress to erythroderma. ${ }^{2}$ Abnormalities in laboratory investigations include leukocytosis, atypical lymphocytes and eosinophilia. Systemic involvement most commonly includes hepatitis, pneumonitis and acute interstitial nephritis; there are also case reports of myocarditis, colitis, pancreatitis and encephalitis as presenting features of the disease. ${ }^{1,2}$

The RegiSCAR score is a diagnostic tool for DRESS syndrome based on seven clinical and laboratory parameters that help determine if the syndrome is an absent, possible, probable or definite diagnosis; it is important to note that eosinophilia may not be present and is not required to make the diagnosis (Box 3). ${ }^{1,2}$

Prognosis depends on patient age, comorbidities and severity of organ involvement. The liver is most commonly affected (involved in $60 \%-80 \%$ of cases), often presenting as hepatomegaly and jaundice. ${ }^{2}$ Liver failure is the leading cause of death in patients with DRESS syndrome, with mortality rates of $5 \%-10 \%{ }^{2}$ Renal involvement is found in $10 \%-30 \%$ of cases, and pneumonitis is seen in $5 \%-25 \% .^{2}$ Hypothyroidism is a late complication that requires protracted monitoring of tests for thyroid function after diagnosis. ${ }^{3}$ Additional late manifestations reported in the literature include type 1 diabetes mellitus, systemic lupus erythematous and autoimmune hemolytic anemia.,

\section{Pathogenesis}

The pathogenesis of DRESS syndrome is only partially understood. Markers for genetic susceptibility have been identified within the HLA complex. ${ }^{7}$ Owing to high co-incidence with cytomegalovirus, Epstein-Barr virus and herpes virus ${ }^{6,7}$ reactivation,

Box 1: Differential diagnosis considered in a returned traveller with fever, rash, hepatitis and eosinophilia*

\begin{tabular}{|c|c|c|c|c|}
\hline \multicolumn{2}{|c|}{ Infectious } & \multirow[b]{2}{*}{ Inflammatory } & \multirow[b]{2}{*}{ Neoplastic } & \multirow[b]{2}{*}{ Drug reaction } \\
\hline Travel related & Travel independent & & & \\
\hline $\begin{array}{l}\text { Viral: hepatitis A, hepatitis B, } \\
\text { hepatitis D and hepatitis E, } \\
\text { dengue fever, hemorrhagic } \\
\text { fever syndromes } \\
\text { - Bacterial: malaria and enteric } \\
\text { infections } \\
\text { - Parasitic: helminth infections }\end{array}$ & $\begin{array}{l}\text { - Viral: Epstein-Barr virus, } \\
\text { cytomegalovirus, HIV } \\
\text { - Bacterial: syphilis }\end{array}$ & $\begin{array}{l}\text { - Autoimmune hepatitis } \\
\text { - Adult-onset Still disease } \\
\text { - Vasculitis, including } \\
\text { atypical presentation of } \\
\text { eosinophilic } \\
\text { granulomatosis with } \\
\text { polyangiitis }\end{array}$ & $\begin{array}{l}\text { Myeloid or lymphoid } \\
\text { neoplasm }\end{array}$ & $\begin{array}{l}\text { Adverse drug reaction to } \\
\text { sulfasalazine }\end{array}$ \\
\hline
\end{tabular}


it is thought that the syndrome may mediate its effects in part through molecular mimicry with cross-reactivity between antigens on drugs and viruses; this stimulates T-cell production and an aggressive host inflammatory response. ${ }^{8}$ The theory that drug hypersensitivity is the cause of drug reaction with DRESS syndrome is supported by the accelerated onset of symptoms in cases with drug rechallenge. ${ }^{7}$

\section{Treatment}

Currently, guidelines for treatment of DRESS syndrome are lacking; the mainstay is withdrawal of the offending agent and supportive care. A retrospective review of 38 cases of the syndrome suggested that patients received benefit with topical corticosteroid creams in mild cases; however, no severity scores were provided to help with early identification of those cases that

\section{Box 2: Results for laboratory investigations}

\begin{tabular}{|c|c|c|c|}
\hline Laboratory test & Reference range & On day of admission & On day 5 of admission \\
\hline Hemoglobin, $g / L$ & $115-155$ & 137 & 115 \\
\hline Mean corpuscular volume, $\mathrm{fL}$ & $82.0-97.0$ & 95.0 & 94.8 \\
\hline Platelet count, $\times 10^{9} / \mathrm{L}$ & $140-400$ & 213 & 245 \\
\hline White blood cell count, $\times 10^{9} / \mathrm{L}$ & $4.00-11.00$ & 7.36 & 8.60 \\
\hline Lymphocytes, $\times 10^{9} / \mathrm{L}$ & $1.0-3.2$ & 1.174 & 2.924 \\
\hline Eosinophils, $\times 10^{9} / \mathrm{L}$ & $0.04-0.4$ & 0.514 & 1.376 \\
\hline Blood film (including thin and thick smears) & & Atypical lymphocytes & - \\
\hline Sodium, $\mathrm{mmol} / \mathrm{L}$ & $135-145$ & 130 & 132 \\
\hline Potassium, $\mathrm{mmol} / \mathrm{L}$ & $3.5-5.0$ & 4.1 & 4.5 \\
\hline Bicarbonate, $\mathrm{mmol} / \mathrm{L}$ & $22-30$ & 26 & 28 \\
\hline Creatinine, $\mu \mathrm{mol} / \mathrm{L}$ & $42-102$ & 55 & 59 \\
\hline Aspartate aminotransferase, IU/L & $7-40$ & 138 & 524 \\
\hline Alanine aminotransferase, IU/L & $10-45$ & 418 & 615 \\
\hline Alkaline phosphatase, IU/L & $35-125$ & 402 & 309 \\
\hline Albumin, $\mathrm{g} / \mathrm{L}$ & $35-50$ & 42 & 35 \\
\hline Bilirubin, total; $\mu \mathrm{mol} / \mathrm{L}$ & $0-23$ & 15 & 55 \\
\hline Bilirubin, direct; $\mu \mathrm{mol} / \mathrm{L}$ & $0-7$ & Not tested & 36 \\
\hline International normalized ratio & $0.9-1.20$ & 1.01 & Not tested \\
\hline C-reactive protein, $\mathrm{mg} / \mathrm{L}$ & $0-5.0$ & 11.7 & Not tested \\
\hline Erythrocyte sedimentation rate, $\mathrm{mm} / \mathrm{h}$ & $0-20$ & 23 & Not tested \\
\hline Complement, g/L & $\begin{array}{l}\text { C3 } 0.79-1.52 \\
\text { C4 } 0.16-0.38\end{array}$ & $\begin{array}{l}\text { C3 } 1.25 \\
\text { C4 } 0.37\end{array}$ & \\
\hline Antineutrophil cytoplasmic antibody & & Negative & \\
\hline Blood cultures & & Negative & \\
\hline Stool cultures & & Negative & \\
\hline Ova and parasites in stool & & Negative & \\
\hline $\begin{array}{l}\text { Serology: hepatitis A, hepatitis B, } \\
\text { hepatitis C, HIV, Epstein-Barr virus, } \\
\text { cytomegalovirus, VDRL }\end{array}$ & & & Positive for hepatitis A IgG only \\
\hline Immunoglobulin (Ig) quantification, g/L & $\begin{array}{l}\text { IgA } 0.82-4.52 \\
\text { IgM } 0.46-3.04 \\
\operatorname{IgG} 7.51-15.60\end{array}$ & $\begin{array}{l}\operatorname{IgA} 1.38 \\
\operatorname{IgM} 0.77 \\
\operatorname{IgG} 11.90\end{array}$ & \\
\hline Ferritin, $\mu \mathrm{g} / \mathrm{L}$ & $12-192$ & 747 & 1426 \\
\hline Autoimmune hepatitis serology & ANA $\leq 1.0$ & $\begin{array}{c}\text { ANA 0.3, ASMA negative, } \\
\text { AMA negative }\end{array}$ & \\
\hline Ultrasonography of abdomen & & & $\begin{array}{l}\text { Periportal inflammation } \\
\text { without hepatosplenomegaly } \\
\text { or biliary disease }\end{array}$ \\
\hline
\end{tabular}


would benefit from topical versus systemic therapy. ${ }^{3}$ In the presence of organ dysfunction, systemic corticosteroids $(0.5-1 \mathrm{mg} /$ $\mathrm{kg} / \mathrm{d}$ ) are often used. Symptoms may persist or increase even after stopping the drug, necessitating prolonged corticosteroid courses. In refractory cases, treatment may require more potent immunosuppression using agents such as cyclosporine, cyclo-

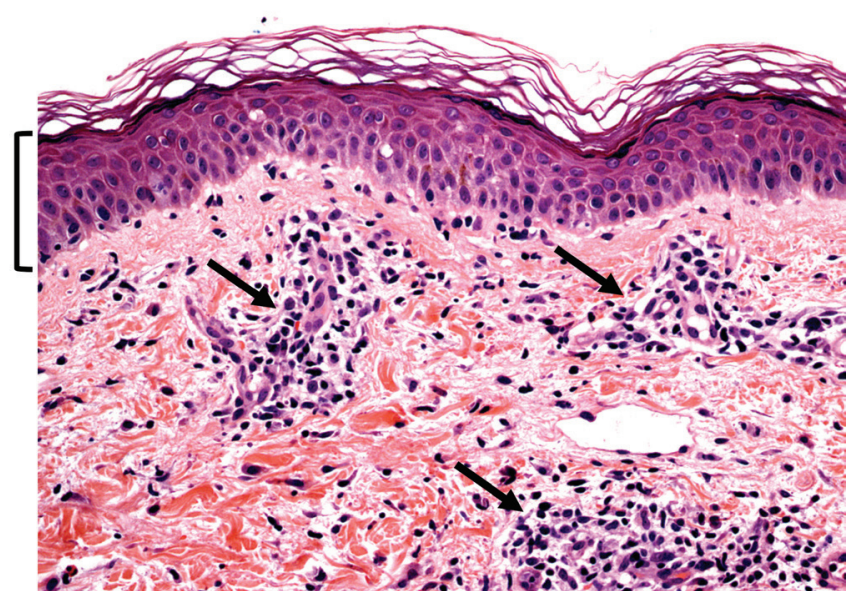

Figure 1: Histologic examination of skin biopsy of the eruption showing focal epidermal spongiosis (or intercellular edema, highlighted in the bracketed region), perivascular lymphocyte infiltration (arrows) and focal interface dermatitis, with lymphocytes aggregated around the dermalepidermal junction. The latter finding has often been reported in the context of drug reaction with eosinophilia and systemic symptoms syndrome. Hematoxylin and eosin stain. Original magnification $\times 400$. phosphamide, mycophonelate mofetil and rituximab, and, in some cases, intravenous immunoglobulin or plasmapheresis. However, use of these agents is not validated by controlled studies and is based on case series and expert opinion only.

Our patient had stopped taking sulfasalazine before she presented to the emergency department, and, during her stay in hospital, her skin eruption slowly resolved with oral antihistamine treatment. Her hepatitis deteriorated, however, with a rise in total and direct bilirubin. Given the high mortality rate in patients with DRESS syndrome who present with hepatitis, we considered treatment with systemic corticosteroids, but we were mindful of the potential for latent strongyloidiasis caused by the Strongyloides stercoralis nematode, which is endemic in Africa, Asia, Southeast Asia, and Central and South America.

Between 1991 and 2001, 77.5\% of immigrants to Canada originated from countries where S. stercoralis is endemic. ${ }^{9}$ Treatment with corticosteroids, in the presence of $S$. stercoralis colonization, can precipitate strongyloides hyperinfection syndrome..$^{10}$ In this syndrome, which carries a mortality rate as high as $87 \%$, invasive filariform larvae precipitate leakage of gut flora from damaged bowel, ${ }^{9}$ disseminating bacterial and fungal infections. Hyperinfection is most commonly seen in patients who are immunosuppressed, including those who received treatment with corticosteroids (regardless of duration of therapy). ${ }^{10}$ Diagnosis in asymptomatic patients involves collection of three consecutive stool samples at 24-hour intervals to identify ova and parasites. However, sensitivity of stool studies is only $50 \% .{ }^{9}$ High-risk patients require serology, which has sensitivity and specificity of $82 \%-95 \%$ and $84 \%-92 \%$, respectively. ${ }^{9}$ Imaging modalities, including CT of

Box 3: The RegiSCAR project diagnostic score for a probable diagnosis of drug reaction with eosinophilia and systemic symptoms syndrome

\begin{tabular}{|c|c|c|c|}
\hline Feature & No & Yes & Unknown \\
\hline Fever $\left(\geq 38.5^{\circ} \mathrm{C}\right)$ & -1 & 0 & -1 \\
\hline Enlarged lymph nodes (two sites or more, $>1 \mathrm{~cm}$ ) & 0 & 1 & 0 \\
\hline Atypical lymphocytes & 0 & 1 & 0 \\
\hline \multicolumn{4}{|l|}{ Eosinophilia } \\
\hline 0.7 to $1.5 \times 10^{9} / \mathrm{L}$ or $10 \%-19 \%$ of white blood cell count & & 1 & \\
\hline$>1.5 \times 10^{9} / \mathrm{L}$ or $\geq 20 \%$ of white blood cell count & & 2 & \\
\hline \multicolumn{4}{|l|}{ Skin rash } \\
\hline Distribution over more than $50 \%$ of body surface area & 0 & 1 & 0 \\
\hline At least two of edema, infiltration, purpura or scale & -1 & 1 & 0 \\
\hline Biopsy suggesting DRESS & -1 & 0 & 0 \\
\hline \multicolumn{4}{|l|}{ Internal organ involved } \\
\hline One & & 1 & \\
\hline Two or more & & 2 & \\
\hline Resolution in more than 15 days & -1 & 0 & -1 \\
\hline $\begin{array}{l}\text { At least three negative results from biologic investigations into } \\
\text { alternative diagnoses }\end{array}$ & 0 & 1 & 0 \\
\hline
\end{tabular}


the thorax, abdomen and pelvis, are not recommended for latent screening for infection caused by Strongyloides.

In our patient, results from stool studies were negative for Strongyloides, and, as we anticipated a two-week delay in obtaining serology results, we decided to treat empirically for Strongyloides infection with ivermectin $(200 \mu \mathrm{g} / \mathrm{kg} / \mathrm{d}$ for two days) before administering prednisone $(1 \mathrm{mg} / \mathrm{kg} / \mathrm{d})$ for the treatment of DRESS syndrome.

\section{Case revisited}

Treatment with corticosteroids led to rapid resolution of our patient's clinical symptoms and biochemical derangements, and we discharged her from hospital with scheduled outpatient follow-up and tapering of prednisone. Ultimately, results from serology testing for Strongyloides were negative.

\section{References}

1. Kardaun SH, Sekula P, Valeyrie-Allanore L, et al. Drug reaction with eosinophilia and systemic symptoms (DRESS): an original multisystem adverse drug reaction. Results from the prospective RegiSCAR study. Br J Dermatol 2013;169:1071-80.
2. Hoetzenecker W, Nägeli M, Mehra ET, et al. Adverse cutaneous drug eruptions: current understanding. Semin Immunopathol 2016;38:75-86.

3. Funck-Brentano E, Duong TA, Bouvresse S, et al. Therapeutic management of DRESS: a retrospective study of 38 cases. J Am Acad Dermatol 2015;72:246-52.

4. Cacoub P, Musette P, Descamps V, et al. The DRESS syndrome: a literature review. Am J Med 2011;124:588-97.

5. Eshki M, Allanore L, Musette P, et al. Twelve-year analysis of severe cases of drug reaction with eosinophilia and systemic symptoms: a cause of unpredictable multiorgan failure. Arch Dermatol 2009;145:67-72.

6. Matta JM, Flores SM, Cherit JD. Drug reaction with eosinophilia and systemic symptoms (DRESS) and its relation with autoimmunity in a reference center in Mexico. An Bras Dermatol 2017;92:30-3.

7. Roujeau JC. Immune mechanisms in drug allergy. Allergol Int 2006;55:27-33.

8. Raithatha N, Mehrtens S, Mouyis M, et al. Rash and fever after sulfasalazine use. BMJ 2014;349:g5655.

9. Lim S, Katz K, Krajden S, et al. Complicated and fatal Strongyloides infection in Canadians: risk factors, diagnosis and management. CMAJ 2004;171:479-84.

10. Myint A, Chapman C, Almira-Suarez I, et al. Strongyloides hyperinfection syndrome in an immunocompetent host resulting in bandemia and death. BMJ Case Rep 2017;Mar 22;2017. pii: bcr2016217911.
Competing interests: None declared.

This article has been peer reviewed.

The authors have obtained patient consent.

Affiliations: Department of Clinical Immunology and Allergy (Jeimy), Western University, London, Ont.; Department of Medicine
(McRae, Pattani), University of Toronto; Division of General Internal Medicine (Pattani), St. Michael's Hospital, Toronto, Ont.

Contributors: Samira Jeimy drafted the manuscript. All of the authors provided patient care in this case, revised the manuscript critically for important intellectual content, gave final approval of the version to be published and agreed to be accountable for all aspects of the work.

Correspondence to: Samira Jeimy, jeimysb@ gmail.com 